\title{
Research and Application of the NX-Based Computer Aided Tolerance Design (CATD)
}

\author{
Jun Liu ${ }^{1, a}$ and Yuemiao Wang ${ }^{2, b}$ \\ ${ }^{1}$ UGS College, Yancheng Institute of Technology, Yancheng, China \\ ${ }^{2}$ School of Mechanical Engineering, Nanjing University of Science and Technology, Nanjing, China \\ aliuj@ycit.cn, ${ }^{b} 524057192 @ q q . c o m$
}

Keywords: Tolerance optimal design, CATD, Display case, NX

\begin{abstract}
As the core part of dimension management, tolerance optimal design plays an increasingly important role in the whole process of product development. As the appearance of CATD, the designer can solve the problem of the dimension of the development and design process. This paper introduced the fundamentals of computer aided tolerance design (CATD) and analyzed its important function in mechanical manufacturing. The paper also proposed an outline of the design process of CATD and the tolerance optimal design process and employed a display case to study the design methods of computer aided tolerance. Finally, the application of tolerance design function in NX was used to show the efficiency of achieving product optimization design.
\end{abstract}

\section{Introduction}

To adapt to the changing customer demand, the traditional mechanical manufacturing make full use of the and the development efforts of the computer and information technology in the increasingly fierce market competition, and is constantly combined with advanced computer technology. And there the technologies of computer aided design, computer aided manufacture, computer aided process and computer integrated manufacturing system etc. successfully appearing in the machinery sector. Mechanical manufacturing process is integrated and concurrent design is introduced to the modern machinery manufacturing. The use of these techniques can greatly improve the product research and development ability, and shorten the product development cycle, improve the quality of mechanical products, and greatly reduce the production cost.

At present, the CIMS and CAD/CAM have made a major breakthrough and the remarkable achievements. But as an important part of the mechanical product design and manufacture process, the mechanical part tolerance design and tolerance design process in domestic basically rely on designer's experience and chart, using the method of analogy artificial or half artificial design. In all kinds of CAD software it can only realize the tolerance-set. Ye and Salustri [1] introduced a new concurrent engineering method for tolerance allocation and constructed a nonlinear optimization model to implement the method. Tolerance Optimal Design is an important part of mechanical design. The tolerance design problem becomes more complex in the presence of alternative processes (or machines) for manufacturing of each dimension. This is because the manufacturing cost-tolerance characteristic differs from processing to processing, and from machine to machine [2]. The tolerance design occupies an important position in the mechanical product design. However tolerance analysis and design research is far behind the development of CAD, CAPP and CAM, which makes it can't adapt to the current development of CAD/CAM integration and CIMS, and to become the key of stopping their further development. So the research of computer aided tolerance design (CATD) is becoming the urgent need.

Computer aided tolerance design (CATD) is to use computer to optimum and control the product dimensions and tolerances in the design and tolerance of mechanical product. Identifying the effects of part variation on the functionality of an assembly (tolerance analysis) is challenging problem involving the competing objectives of achieving acceptable manufacturing cost and desired product quality, as well as the functional constraints imposed by the product design requirements [3,4]. CATD is one of the key technologies of CAD/CAM integration. It has important effect to the 
quality of the product and manufacturing cost.

\section{The design procedure of CTAD}

The representation, analysis and distribution of tolerance must depend on specific products production and manufacturing environment, so the computer aided tolerance design is based on a certain product modeling system. Tolerance optimization is a process of repeated revision and simulation analysis. After many times of iteration, it can obtain a product distribution scheme tending to economic and reasonable. The design flow of CTAD is shown as fig.1.

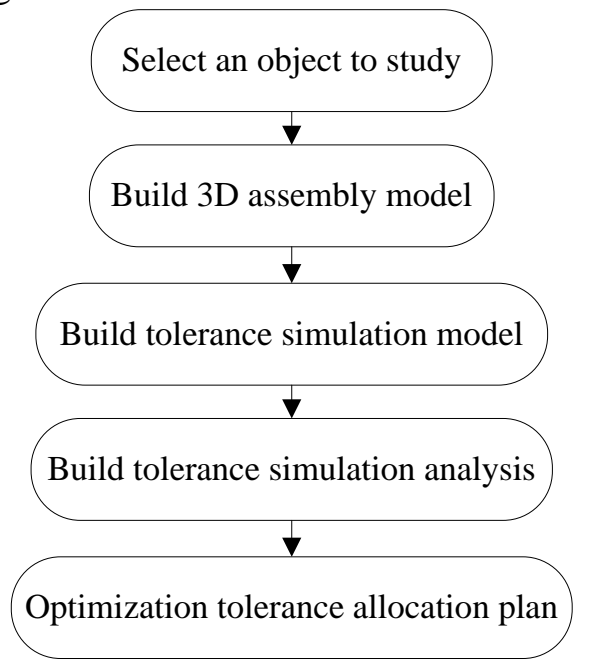

Fig.1 The design flow of CTAD

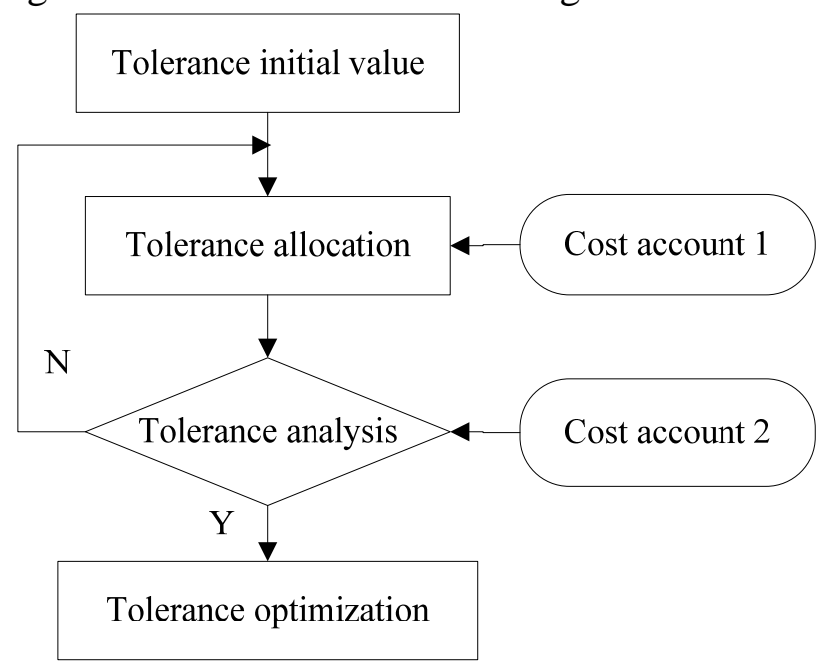

Fig.2 Tolerance optimal design

Tolerance design includes tolerance distribution and analysis. Tolerance design is based on the tolerance design function, and the so-called tolerance design function refers to the functional relationship of dimensions of assembly technical requirements and product functional requirements etc, such as the mathematical said of axle and hole fitting parts' fit clearance.

Tolerance optimization design is essentially a mathematical programming problem which makes the dimension chain composed of parts manufacturing cost to be the least as the goal and makes design technology condition and expected assembly success rate as constraint, but also a random variable optimization problem. The process can be shown as fig.2. Tolerance analysis is a link of tolerance optimization design, and tolerance analysis efficiency directly decides the efficiency of tolerance optimization design efficiency.

\section{The display case}

The display case is the pictorial representation of tolerance feature object. When the user needs more display of the same benchmark in a single view or multiple view case, the display case will be very useful. As the original mathematical model of tolerance feature is automatically inherited to the engineering drawing, the display case is often to be used. According to actual condition, the display case and tolerance characteristic in the operation are used alternately by user.

It appears in the window as the graphic display mode of tolerance characteristics, which is shown in fig.3. A tolerance feature allows to using more display case presentation, so that users apply it in different view, such as modeling or drawing application. It can own multiple performances in the view. In fig.3, reference A is marked twice as display of one tolerance characteristic in the figure, and the mark is the display case. In the left figure, reference A is marked in the form of flatness in the top viewport. 

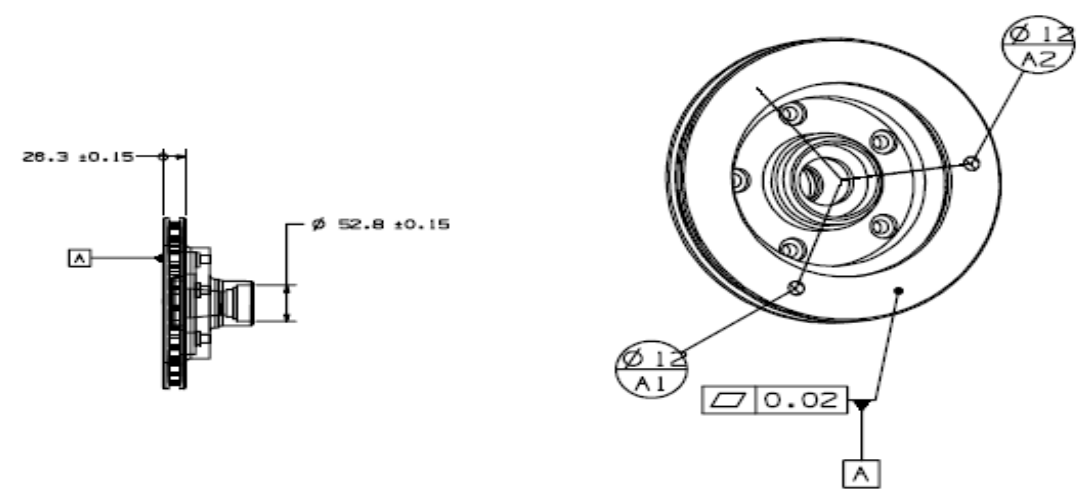

Fig.3 The display case

\section{The tolerance information tagging based on NX}

Geometric shape and position tolerance (GD\&T) is a based on the principle of sound engineering and manufacturing practice. The geometric tolerance module of NX can make user capture the tolerance information from the design analog and is related to the corresponding geometrical element. There are two kinds of features in NX, and they are Geometric characteristic and tolerance characteristic. In NX, it uses geometric tolerance module to make tolerance information load to the model.
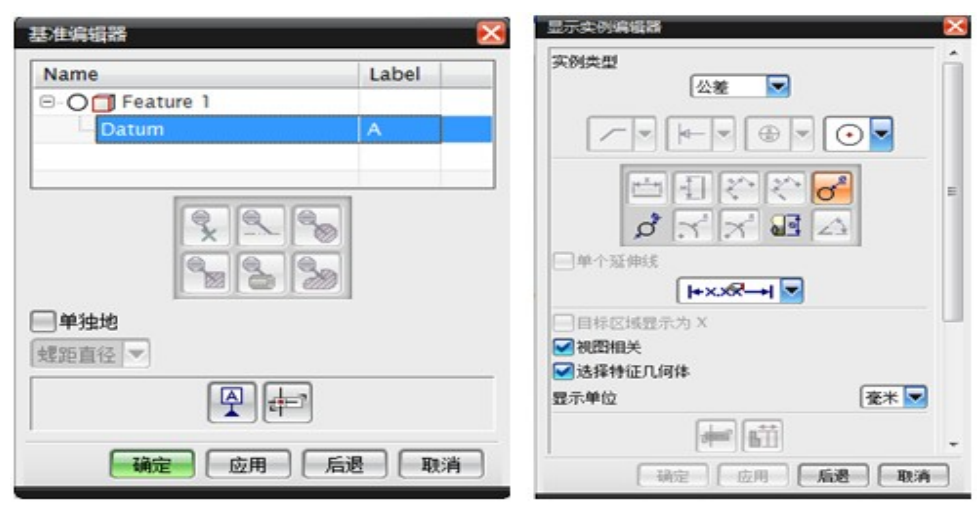

Fig.4 Datum editor and display case editor

In theory, the datum is different from the precise point, shaft or surface of real geometric characteristic, to locate the created geometrical characteristic. Benchmark must be determined before the characteristic, such as tolerance characteristic, tolerance sash and benchmark goal. The research labels tolerance information with three steps, and they are datum feature, display case, and tolerance feature. Fig. 4 is the windows of datum editor and display case editor. Fig.5 is the windows of tolerance editor.

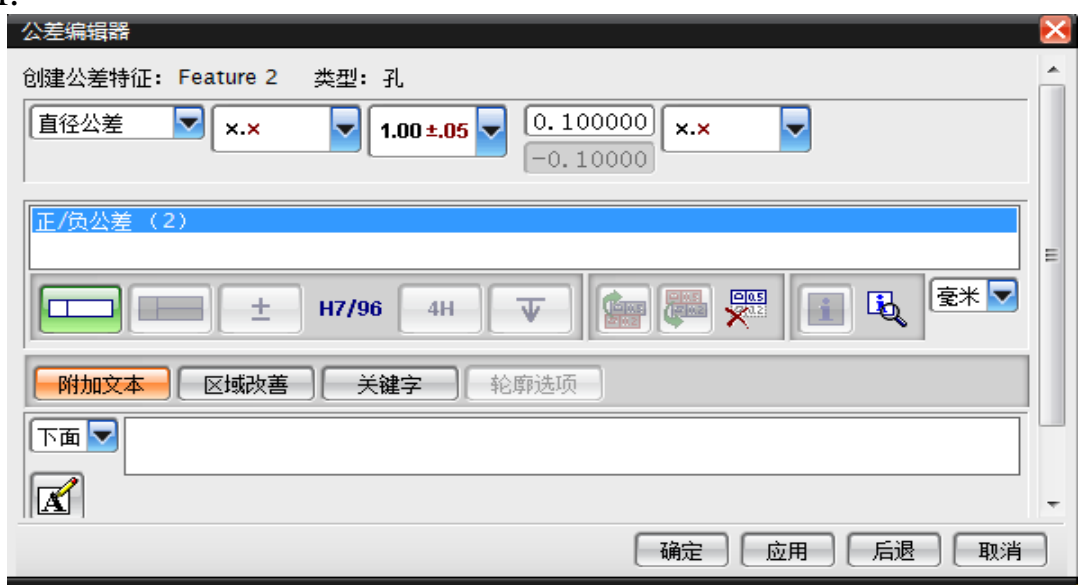

Fig.5 Tolerance editor 


\section{Summary}

In all links of production design and manufacture, dimension management process is a very important part. And tolerance optimization design plays a more and more important role as the core part of dimension management of in the product development process. Along with the CATD's appearing, designer can fundamentally solve dimension problem in the process of development and design, and maximally reduce later passive modification to reduce cost, and at the same time, to accelerate the speed of production spreading to market. The research puts forward the design methods of CATD, and makes use of the display case to introduce the design method and application of CATD based on NX, so as to achieve optimal design of product. But the research is about tolerance design of the rigid parts, so the research should be suitable for tolerance model and tolerance analysis of flexible pieces.

\section{Acknowledgment}

The project was supported by research fund of Key Laboratory for Advanced Technology in Environmental Protection of Jiangsu Province.

\section{References}

[1] B. Ye, F.A. Salustri: Simultaneous tolerance synthesis for manufacturing and quality. Research in Engineering Design 2003; 14(2):98-106.

[2] K. Sivakumar, C. Balamurugan, S. Ramabalan: Simultaneous optimal selection of design and manufacturing tolerances with alternative manufacturing process selection. Computer-Aided Design 2011; 43 (2): 207-218.

[3] Y.S. Hong, T.C. Chang: A comprehensive review of tolerancing research. International Journal of Production Research 2002; 40(11):2425-59.

[4] M. Mazur, M. Leary, A. Subic: Automated simulation of stochastic part variation to identify key performance characteristics of assemblies. In: Proceedings ofthe 6th IPROMS virtual conference. 2010. 